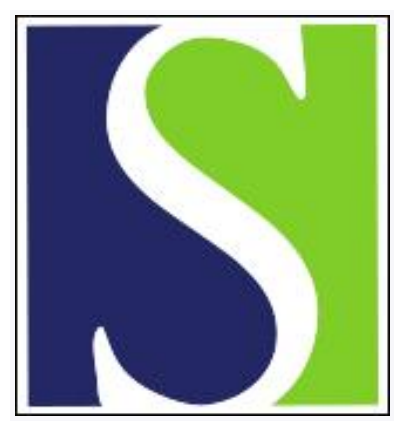

Scand J Work Environ Health 1999;25(4):342-350

https://doi.org/10.5271/sjweh.444

Issue date: Aug 1999

Neuropsychological effects associated with exposure to mercury vapor among former chloralkali workers

by Mathiesen T, Ellingsen DG, Kjuus $\mathrm{H}$

Key terms: ceased exposure; cumulative mercury exposure; neurobehavioral effect

This article in PubMed: www.ncbi.nlm.nih.gov/pubmed/10505660

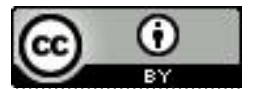




\title{
Neuropsychological effects associated with exposure to mercury vapor among former chloralkali workers
}

\author{
by TMathiesen, PSyD, ${ }^{1,2}$ DG Ellingsen, MD, ${ }^{1.3}$ H Kjuus, MD ${ }^{1,3}$
}

\begin{abstract}
Mathiesen T, Ellingsen DG, Kjuus $H$. Neuropsychological effects associated with exposure to mercury vapor among former chloralkali workers. Scand J Work Environ Health 1999;25(4):342-350.
\end{abstract}

\begin{abstract}
Objectives This investigation studied possible neuropsychological effects among former chloralkali workers with past exposure to mercury vapor.

Methods Seventy-five formerly exposed workers who had been examined with an extensive neuropsychological test battery were compared with 52 referents frequency-matched for age. The tests measured general cognitive function, motor and psychomotor function, attention, memory, and learning. The groups were similar in educational level, age, and verbal comprehension. The mean exposure time to mercury vapor in the index group was 7.9 (range $1.1-36.2$ ) years with an annual mean urinary mercury concentration of 539 (range 41-2921) nmol/(1 . year). The mean time since the cessation of exposure was 12.7 (range 1.0-35.0) years.

Results Performance on the grooved pegboard (dominant hand 75.8 versus 70.9 seconds, $P<0.05$; nondominant hand 82.2 versus 76.3 seconds, $P=0.02$ ) and the Benton visual retention test (mean number of correct reproductions 6.9 versus $7.5, \mathrm{P}<0.05$ ) was poorer among the formerly exposed workers when compared with the referents. In addition the subjects who had experienced the highest intensity of exposure [cumulative urinary mercury index $\geq 550 \mathrm{nmol} /(1$. year $)]$ had a poorer performance on the trailmaking test, part A and $\mathrm{B}$, on the digit symbol test, and on the word pairs test (retention errors).

Conclusions The presented results suggest a slight persistent effect of mercury vapor exposure on the central nervous system, mainly involving motor functions and attention, but also possibly related to the visual system. Previous exposure does not seem to have affected the workers' general intellectual level or their ability to reason logically.
\end{abstract}

Key terms ceased exposure, cumulative mercury exposure, neurobehavioral effects.

The central nervous system (CNS) is a well known target for mercury vapor toxicity. Among the early signs of toxic effects are tremor and various neuropsychiatric symptoms (1). Neurobehavioral effects of occupational exposure have been described as falling into the 3 major groups of alterations in emotional state, effects on cognitive functions, and effects on motor functions $(1,2)$. Ongoing exposure to lower concentrations of mercury vapors has been associated with increased hand or finger tremor, subclinical changes in coordination, neuromuscular functions, and deficits in memory and attention (3-20). Magos (21) suggested that it may be a mistake to relate defects to exposure estimates valid at a time when the possibility of higher exposure in the past cannot be excluded. Only a few studies on populations currently exposed to mercury vapors have addressed the magnitude of effects related to previous exposure when current exposure was assessed.

This study focuses on nervous system effects after the cessation of exposure to mercury vapors. Little research on previously exposed subjects has been published. There is, however, evidence of persisting neurological abnormalities in subjects with past exposure (22--25). In addition, evidence of persisting neurobehavioral impairment in former Japanese mercury miners, especially motor coordination, has been presented (26). The workers included in the study also had a history of clinically overt mercury poisoning, and the reported air mercury concentrations at the time of exposure were usually above 1.0 $\mathrm{mg} / \mathrm{m}^{3}$. An American study of 247 workers in a lithiumproducing plant who were previously exposed to mercury vapors also reported slight effects of exposure on

1 Department of Occupational and Environmental Medicine, Telemark Central Hospital, Skien, Norway.

2 Current address: Department of Adult Habilitation, Ullevål Hospital, Oslo, Norway.

3 Current address: National Institute of Occupational Health, Oslo, Norway.

Reprint requests: Dr Helge Kjuus, National Institute of Occupational Health, PO Box 8149 Dep, 0033 Oslo, Norway. [E-mail: Helge.Kjuus@stami.no] 
motor functions without a concomitant impairment of cognitive functions (27). More than $40 \%$ of the subjects had had a recorded urinary mercury concentration exceeding $3000 \mathrm{nmol} / \mathrm{l}$ at least once, indicating that they had been exposed to high concentrations of mercury. The question remains to be further elucidated whether the neurobehavioral effects related to motor and cognitive functions associated with ongoing exposure to mercury vapors at lower levels are persistent.

After the closure of a mercury-based chloralkali plant which started production in 1947 and was closed in 1987, former workers were invited to participate in a comprehensive study on the possible health effects related to previous exposure to mercury vapors. A cross-sectional study was performed during 1989-1990. The main results of the neurological and neurophysiological parts of that study were an increased prevalence of reduced distal sensation, impaired coordination, postural tremor, and signs indicating station and gait disturbances $(24,25)$. Furthermore, a dose-related decrease of the conduction velocities of the median motor and sensory nerves was observed, together with reduced amplitudes of the sural nerve. Measurements also showed that the visually evoked response was altered in the previously exposed workers. The aim of our present investigation was to study neuropsychological functions among the same former chloralkali workers in relation to their past exposure to mercury vapors.

\section{Subjects and methods}

\section{Subjects}

The overall study design has been presented earlier (25). Briefly, the main inclusion criteria for the former chloralkali workers were men below 65 years of age at the time of examination, exposed to mercury vapors for more than 1 year between 1947 and 1987, and known urinary mercury measurements from at least 43 -monthly periods during employment. One hundred and thirty subjects identified from the company's records met these criteria, of whom 7 were deceased and 5 had moved to distant parts of the country and were thus not considered for inclusion. The main exclusion criteria were alcohol abuse, major head injuries (unconsciousness $>6$ hours), metabolic disorders, neurological, psychiatric or other diseases causing severe disability, and exposure to other known occupational neurotoxicants above specified levels. Twenty-four subjects were excluded altogether, of whom 2 were excluded owing to diseases of the nervous system ( 1 because of encephalopathy with epilepsy diagnosed 1 year after the start of exposure to mercury vapors and 1 because of episodes of cerebral ischemia).

The reference group comprised randomly selected male nitrate fertilizer workers employed by the same company as the former exposed workers. They were frequency-matched for age. None of the referents had ever been occupationally exposed to mercury compounds. Identical exclusion criteria were applied to the exposed subjects and the referents.

Of the 77 former chloralkali workers included in the neurological examinations (participation rate $\approx 82 \%$ ), 2 subjects declined to be neuropsychologically examined. One of the 53 referents taking part in the neurological examinations (participation rate $\approx 86 \%$ ) was excluded from the neuropsychological examinations owing to a low general intellectual level, which caused obvious difficulties in understanding the instructions during the test session.

Initially, all the subjects underwent a clinical interview which emphasized their job history, life-style habits, and medical history. A brief clinical examination was also conducted. The current concentrations of mercury in urine and whole blood and lead in whole blood were recorded for all the subjects. Details of the sampling and analytical methods of the trace elements have been presented elsewhere (28).

No major differences were found between the exposed group and the referents for age, duration of general education, or alcohol consumption (table 1). Furthermore no significant differences were found for dental amalgam status or fish consumption (28). The prevalence of reported earlier mild concussion of the brain was higher among the former chloralkali workers $(28 \%)$ than among the referents $(15.4 \%)$. Three subjects with a long

Table 1. Characteristics of 75 former mercury-exposed subjects and 52 referents.

\begin{tabular}{|c|c|c|c|c|}
\hline \multirow[t]{2}{*}{ Characteristic } & \multicolumn{2}{|c|}{ Exposed } & \multicolumn{2}{|c|}{ Referents } \\
\hline & Mean & SD & Mean & SD \\
\hline Age (years) & 44.7 & 11.6 & 45.5 & 10.8 \\
\hline Education (years) & 9.5 & 1.8 & 9.5 & 1.8 \\
\hline Ethanol consumption (l/month) & 0.3 & 0.4 & 0.2 & 0.2 \\
\hline $\begin{array}{l}\text { Current urinary mercury } \\
\text { concentration }(\mathrm{nmol} / \mathrm{mmol}\end{array}$ & & & & \\
\hline creatinine) & 1.8 & 1.3 & 1.2 & 0.6 \\
\hline $\begin{array}{l}\text { Current blood mercury } \\
\text { concentration (nmol/l) }\end{array}$ & 26.1 & 8.1 & 27.6 & 10.1 \\
\hline Current blood lead & & & & \\
\hline concentration $(\mu \mathrm{mol} / /)$ & 0.3 & 0.1 & 0.3 & 0.1 \\
\hline Mercury exposure (years) & 7.9 & 6.8 & . & . \\
\hline Years since last exposure & 12.7 & 11.7 & . & . \\
\hline $\begin{array}{l}\text { Cumulative urinary mercury } \\
\text { concentration (nmol/l) }\end{array}$ & 3244 & 3178 & 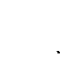 & . \\
\hline Mean urinary concentration & & & & \\
\hline per year $[\mathrm{nmol} /(\mathrm{l} \cdot$ year $)]$ & 539 & 466 & . & . \\
\hline Earlier concussions (\%) & 28.0 & . & 15.4 & . \\
\hline Current smokers (\%) & 57.1 & . & 67.9 & r \\
\hline Current shift workers (\%) & 25.3 & . & 42.3 & . \\
\hline
\end{tabular}


duration of unconsciousness, but which was below the exclusion criterion ( $>6$ hours), were evaluated clinically after all the examinations, and they did not show particularly poorer performance. The prevalence of shift workers was higher in the reference group (42.3\%) than in the exposed group (25.3\%).

\section{Exposure assessment}

The plant started production in 1947 and was closed in 1987. Biological monitoring of the workers had been performed since 1948. The historical exposure assessment for the previously exposed workers is based on more than 2300 urinary mercury measurements.

The main indicator of past exposure was a cumulative urinary mercury index (cum U-Hg), which was calculated for each exposed person. This index represents the individual mean urinary mercury concentration for each year of exposure and for all years added together (expressed as nanomoles per liter). A detailed description of the mercury exposure and the calculation of the cumulative mercury exposure has been reported elsewhere (25).

As the cumulative exposure index is not only related to the duration, but also to the intensity of exposure, 2 other exposure indicators were used. These were the "duration of exposure" in months, and the "intensity of exposure" calculated as the mean urinary mercury concentration for each year of exposure (cum U-Hg/year, expressed as nanomoles per liter per year).

The mean duration of exposure was 7.9 (range 1.136.2 ) years, and the time since exposure cessation averaged 12.7 (range $1-35$ ) years. The mean cumulative urinary mercury exposure was 3244 (range 167-17229) $\mathrm{nmol} / \mathrm{l}$. The individual mean intensity of exposure (cum $\mathrm{U}-\mathrm{Hg} /$ year) was 539 (range $41-2921) \mathrm{nmol} /(\mathrm{l} \cdot$ year) (table 1).

\section{Neuropsychological test battery}

Tests reported to be sensitive to ongoing mercury exposure were included. Likewise tests considered to be nonsensitive to neurotoxins and, finally, tests making it possible to discover a possible differential diagnosis were included $(29,30)$. Both computerized and noncomputerized tests were used. The neuropsychological tests have been grouped by the assumed principal function measured in the following description, since most tests involve several different capacities.

General intellectual function. The vocabulary test (WAISR) consisted of 35 words of increasing difficulty that had to be defined or explained (31). The test gave an estimate of verbal and general intellectual ability.

The similarities test (WAIS-R) consisted of 14 pairs of words (31). The task was to say what each pair of words had in common, preferably with the closest denominator. The test measured the ability of verbal concept formation and reasoning skills.

The picture completion test (WAIS-R) consisted of 20 cards with pictures (31). The task was to say what was missing in each picture within a 20 -second time limit. The test measured visuoperceptual analysis.

Memory and learning. The digit span test (WAIS-R) involved repeating orally presented digits either forwards or backwards (31). The WAIS-R score added forward and backward performance. Digits forward and digits backward expressed the actual length of the span. Digits forward measured attention span, while digits backward involved both a memory component and a reversing operation (mental double-tracking).

The word pairs test consisted of 15 cards with 1 word on each side forming pairs (32). After the initial presentation of all the cards, the first word in each pair was shown. The task was to say the associated word within 10 seconds. The test measured association learning and the delayed recall of verbal material.

In the serial digit learning test (SDL-8) (33) a string of 8 digits was presented orally, and the task continued until the string was repeated correctly in 2 consecutive trials or until 12 trials were performed. SDL- 8 assesses short term memory and learning. Incidental memory was tested by asking the subjects to supply from memory as many as possible of the 9 symbols used in the digit symbol test (WAIS-R) immediately after the completion of the entire matrix (34).

The Benton visual retention test (form $\mathrm{C}$, adm $\mathrm{A}$ ) consisted of 10 cards containing 1 to 3 figures with increasing difficulty (35). After an exposure of 10 seconds, the task was to reproduce each card by drawing. The number of correct reproductions and errors was recorded. This test involves immediate memory span, visuospatial perception, visuomotor response, and visual and verbal conceptualization (29).

The Kimura recurring figures test consisted of 160 cards with geometric or irregular nonsense figures (36). First, 20 different cards were presented. Among the remaining 140 cards, 8 of the initial 20 occurred 7 times mixed with 84 new (one-of-a-kind) figures. False positive responses were subtracted from the correct responses to give the total score. This test is a test of visual memory requiring a recognition response; hence it is independent of drawing skills.

Tests for perceptual-motor speed and reaction time. In part A of the trailmaking test (29), the task was to connect consecutively numbered circles by drawing lines between them, while part $\mathrm{B}$ required an alternation between 2 sequences, with numbered and lettered circles respectively. The time taken to complete the test and the number of errors were recorded. This test involves 
attention, motor speed, visual scanning, and visuomotor tracking.

Digit symbol (WAIS-R) is a symbol substitution task (31). Based on a printed key the subject was asked to combine 9 symbols with the corresponding 9 digits. The WAIS-R raw score is the number of correctly placed symbols in 90 seconds. The position after 90 seconds was marked, but the whole worksheet was completed. The test measures motor speed, visuomotor coordination, visual scanning, and sustained attention under time pressure.

In the simple reaction-time test (NES 2) (37), the task was to press a button as fast as possible when a large square appeared on the computer screen. Individual reaction-time latencies were recorded. The mean reaction time, omitting the first block of trials, was used by us. This test measures visuomotor speed and attention.

In the continuous performance test (NES 2) (37), five different letters have flashed briefly on a screen in random order. The task was to push a button whenever the letter S appeared. The response latencies (mean RT) for each critical trial, but omitting the first block of trials, were used. This test measures sustained visual attention.

Manual dexterity and visuomotor coordination. In the hand-eye coordination test (NES 2) (37), the task was to trace over a sine wave pattern on a screen using a joystick in the dominant hand. A cursor moved horizontally at a constant velocity while the subject controlled the vertical motion. The deviations in the vertical distance from the set line were recorded. The mean of 2 test trails was used. This test measures visuomotor accuracy and motor coordination ability.

The grooved pegboard (Kløve/Matthews Motor Steadiness Battery) consisted of a small board with $5 \times 5$ holes with randomly oriented slots and small pegs with a ridge along 1 side (38). The pegs must be turned into position in order for them to fit correctly in the holes. The completion time was recorded. The test measures manual dexterity and complex motor coordination.

The static steadiness test (Kløve/Matthews Motor Steadiness battery) consisted of a metal plate with 9 holes

Table 2. WAIS-R results (age-scaled scores) among 75 former mercury exposed workers and 52 referents in the analysis of variance.

\begin{tabular}{lrrrrrr}
\hline \multirow{2}{*}{ Testa } & \multicolumn{2}{c}{ Exposed } & & \multicolumn{2}{c}{ Referents } & \multirow{2}{*}{ P-value } \\
\cline { 2 - 3 } & Mean & SD & & Mean & SD & \\
\hline Similarities & 10.2 & 2.2 & & 10.2 & 2.0 & 0.99 \\
Vocabulary & 8.8 & 1.4 & 8.7 & 1.2 & 0.80 \\
Digit span & 8.0 & 2.3 & 8.5 & 2.1 & 0.18 \\
Picture completion & 9.4 & 2.2 & & 9.1 & 1.7 & 0.38 \\
Block design & 11.0 & 2.9 & 10.7 & 2.5 & 0.49 \\
Digit symbol & 8.3 & 2.1 & 8.5 & 1.8 & 0.59 \\
\hline
\end{tabular}

${ }^{a} \mathrm{~A}$ high score indicates good performance. with decreasing diameters from 13 to $2.5 \mathrm{~mm}$. The task was to hold an electric pen in each hole for 15 seconds without touching the metal plate. The measures obtained were the number of touches and touch time. The summation scores for all 9 holes were used. The test measures intentional tremor.

Visuospatial ability. The block design test (WAIS-R) (31) uses 4 or 9 cubes colored red on 2 sides, white on 2 sides and red or white on 2 sides. The task is to construct 9 geometric designs with increasing levels of difficulty. Bonuses are given for fast performance. The test measures abilities in visuospatial organization, planning, and construction.

The results on the WAIS-R subtests have been presented in age-scaled scores (31). American norms were used owing to a lack of Norwegian ones for the revised edition. For all the other tests, raw scores have been used owing to incomplete norms for several tests.

Table 3. Neuropsychological test results of the 75 mercury exposed workers and 52 referents in the analysis of variance.

\begin{tabular}{|c|c|c|c|c|c|}
\hline \multirow[t]{2}{*}{ Test } & \multicolumn{2}{|c|}{ Exposed } & \multicolumn{2}{|c|}{ Referents } & \multirow[t]{2}{*}{ P-value } \\
\hline & Mean & SD & Mean & SD & \\
\hline \multicolumn{6}{|l|}{ Digits } \\
\hline $\begin{array}{l}\text { Forwarda }(\mathrm{N}) \\
\text { Backward }^{\mathrm{a}}(\mathrm{N})\end{array}$ & $\begin{array}{l}5.6 \\
4.4\end{array}$ & $\begin{array}{l}1.1 \\
1.3\end{array}$ & $\begin{array}{l}5.9 \\
4.7\end{array}$ & $\begin{array}{l}1.1 \\
1.2\end{array}$ & $\begin{array}{l}0.35 \\
0.31\end{array}$ \\
\hline $\begin{array}{l}\text { Serial digit learning } \\
\text { Word pairs }\end{array}$ & \multicolumn{4}{|c|}{ Word pairs ${ }^{b}$} & 0.80 \\
\hline $\begin{array}{l}\text { Learning errors } \\
\text { Retention errors }\end{array}$ & $\begin{array}{r}19.6 \\
5.9\end{array}$ & $\begin{array}{r}14.3 \\
3.0\end{array}$ & $\begin{array}{r}18.5 \\
5.4\end{array}$ & $\begin{array}{r}15.3 \\
3.3\end{array}$ & $\begin{array}{l}0.67 \\
0.36\end{array}$ \\
\hline \multicolumn{6}{|l|}{ Benton visual retention test } \\
\hline $\begin{array}{l}\text { Correct }^{\mathrm{a}}(\mathrm{N}) \\
\text { Errors }^{\mathrm{b}}(\mathrm{N})\end{array}$ & $\begin{array}{l}6.9 \\
4.5\end{array}$ & $\begin{array}{l}1.5 \\
2.7\end{array}$ & $\begin{array}{l}7.5 \\
4.0\end{array}$ & $\begin{array}{l}1.4 \\
2.3\end{array}$ & $\begin{array}{r}0.046 \\
0.26\end{array}$ \\
\hline $\begin{array}{l}\text { Kimura recurring figures test, } \\
\text { total score }(N)\end{array}$ & 31.2 & 10.3 & 31.8 & 9.0 & 0.74 \\
\hline Incidental memorya,c $(\mathrm{N})$ & 6.7 & 2.1 & 7.1 & 1.6 & 0.22 \\
\hline Digit symbol, total time $e^{b, c}(s)$ & 207.1 & 67.9 & 194.7 & 46.8 & 0.23 \\
\hline \multicolumn{6}{|l|}{ Trailmaking test ${ }^{b}$} \\
\hline Part A (s) & 37.3 & 18.8 & 33.7 & 12.5 & 0.23 \\
\hline Part B (s) & 114.6 & 71.0 & 100.3 & 53.5 & 0.20 \\
\hline Simple reaction timet, $(\mathrm{ms})$ & 238.6 & 39.0 & 225.9 & 30.0 & 0.050 \\
\hline $\begin{array}{l}\text { Continuous performance } \\
\text { test } t^{b, c}(\mathrm{~ms})\end{array}$ & 404.0 & 44.9 & 395.2 & 40.1 & 0.26 \\
\hline \multicolumn{6}{|l|}{ Grooved pegboard, time (s) } \\
\hline $\begin{array}{l}\text { Dominant hand } d^{\mathrm{b}, \mathrm{c}} \\
\text { Nondominant hand }\end{array}$ & $\begin{array}{l}75.8 \\
82.2\end{array}$ & $\begin{array}{l}16.0 \\
17.5\end{array}$ & $\begin{array}{l}70.9 \\
76.3\end{array}$ & $\begin{array}{l}11.6 \\
11.8\end{array}$ & $\begin{array}{l}0.048 \\
0.024\end{array}$ \\
\hline Hand-eye coordination test ${ }^{h, c}$ & 1.9 & 0.4 & 1.9 & 0.4 & 0.81 \\
\hline \multicolumn{6}{|l|}{ Static steadiness } \\
\hline $\begin{array}{l}\text { Time }(\log ) \\
\text { Number }(\log )\end{array}$ & $\begin{array}{l}0.6 \\
1.7\end{array}$ & $\begin{array}{l}0.5 \\
0.4\end{array}$ & $\begin{array}{l}0.6 \\
1.7\end{array}$ & $\begin{array}{l}0.3 \\
0.3\end{array}$ & $\begin{array}{l}0.72 \\
0.99\end{array}$ \\
\hline \multicolumn{6}{|l|}{ Nondominant hand ${ }^{b}$} \\
\hline $\begin{array}{l}\text { Time }(\log ) \\
\text { Number }(\log )\end{array}$ & $\begin{array}{l}0.8 \\
1.8\end{array}$ & $\begin{array}{l}0.4 \\
0.4\end{array}$ & $\begin{array}{l}0.7 \\
1.8\end{array}$ & $\begin{array}{l}0.3 \\
0.3\end{array}$ & $\begin{array}{l}0.43 \\
0.78\end{array}$ \\
\hline
\end{tabular}

A high score indicates good performance.

- A low score indicates good performance.

- 74 exposed subjects on these tests.

Scand J Work Environ Health 1999, vol 25 , no 4 


\section{Test procedures}

The examinations were performed individually in a quiet room, always by the same psychologist (TM). The test session started at 0900 and lasted an average of about 4 hours. Tests were always administered in the same sequence, and everyone was given a break about halfway through. The testing and scoring were performed without knowledge of exposure status. For the persons working shifts, the examinations took place at a minimum of 3 days, often more, since the last night shift.

\section{Statistics}

The distributions of the measured parameters of the static steadiness test were skewed, and consequently they were log-transformed to allow the use of parametric test methods. Group comparisons were performed with an analysis of variance (ANOVA). When more than 2 groups were compared, the least square difference was calculated to assess which 2 groups differed significantly from each other. In order to control for potential confounding, a simple factorial ANOVA was performed which introduced current alcohol consumption (1/month), age, vocabulary (age-adjusted scores), head injuries (yes,no), and shift work (yes,no) as covariates. The chosen procedure was hierarchical, and the main effect (exposure) was entered with the effects of the covariates. A multiple linear regression analysis (stepwise) was carried out for all the subjects. Dependent variables were the neuropsychological effect measures. Age, current alcohol consumption (1/month), head injuries (yes;no), shift work (yes,no), vocabulary (age-adjusted scores), months exposed, and intensity of exposure (cumulative urinary mercury index) were included as independent variables.

The level of significance was set at 0.05 (2-tailed). All statistical processing was carried out on a personal computer using the statistical data SPSS 7.5® package for Windows(B).

\section{Results}

None of the WAIS-R subtests discriminated significantly between all the exposed subjects and all the referents (table 2, see page 345). General intellectual function, as measured by the vocabulary, similarities, and picture completion tests, was similar in the 2 groups.

Table 4. Neuropsychological test results for the 52 referents, the 50 workers with low cumulative exposure (cum U- $\mathrm{Hg}<3000 \mathrm{nmol} / \mathrm{I}$ ) and the 25 workers with high cumulative exposure (cum U-Hg $\geq 3000 \mathrm{nmol} / \mathrm{I}$ ). (MA = mean adjusted for covariates, cum U-Hg =cumulative urinary mercury concentration)

\begin{tabular}{|c|c|c|c|c|c|c|c|c|c|c|c|c|c|c|c|c|c|c|c|c|c|}
\hline \multirow[t]{3}{*}{ Group } & \multirow{2}{*}{\multicolumn{2}{|c|}{$\begin{array}{c}\text { Age } \\
\text { (years) }\end{array}$}} & \multirow{2}{*}{\multicolumn{2}{|c|}{$\begin{array}{l}\text { Years since } \\
\text { exposure } \\
\text { cessation }\end{array}$}} & \multirow{2}{*}{\multicolumn{2}{|c|}{ Vocabulary }} & \multicolumn{7}{|c|}{ Benton visual retention test } & \multicolumn{8}{|c|}{ Grooved pegboard test } \\
\hline & & & & & & & \multicolumn{3}{|c|}{ Correct (N) } & \multicolumn{4}{|c|}{ Errors $(\mathrm{N})$} & \multicolumn{4}{|c|}{ Dominant (s) } & \multicolumn{4}{|c|}{ Nondominant (s) } \\
\hline & Mean & SD & Mean & SD & Mean & SD & Mean & SD & $\begin{array}{c}\mathrm{P}- \\
\text { value }\end{array}$ & Mean & MA & $\mathrm{SD}$ & $\begin{array}{c}\mathrm{P}- \\
\text { value }\end{array}$ & Mean & MA & SD & $\begin{array}{c}\text { P. } \\
\text { value }\end{array}$ & Mean & MA & SD & $\begin{array}{c}\mathrm{P}- \\
\text { value }\end{array}$ \\
\hline Referentsa & 45.5 & 10.8 & . & . & 8.7 & 1.2 & 7.5 & 1.4 & 0.03 & 4.0 & 4.0 & 2.3 & 0.01 & 70.9 & 71.1 & 11.6 & 0.002 & 76.3 & 77.1 & 11.8 & 0.01 \\
\hline $\begin{array}{l}\text { Low } \\
\text { exposed } \\
\text { Hiah }\end{array}$ & 41.9 & 11.0 & 12.9 & 11.7 & 8.7 & 1.3 & 7.1 & 1.5 & & 4.0 & 4.2 & 2.5 & 0.02 & 72.8 & 75.2 & 14.1 & 0.01 & 80.3 & 81.6 & 17.5 & \\
\hline exposed & 50.5 & 10.6 & 12.2 & 12.0 & 9.0 & 1.6 & 6.7 & 1.6 & & 5.5 & 4.9 & 2.9 & & 81.6 & 76.5 & 18.1 & & 86.1 & 81.8 & 17.2 & \\
\hline P-value & & & & & & & 0.06 & & & 0.01 & & & & 0.001 & & & & 0.01 & & & \\
\hline
\end{tabular}

a Least square difference $(P<0.05)$, referring to comparisons between referents and workers with high exposure.

beast square difference $(P<0.05)$, referring to comparisons between workers with low and high exposure.

c Level of significance between the groups after adjustment for potential confounders (age, alcohol consumption, head injuries, shift work, vocabulary).

Table 5. Neuropsychological test results according to the mean level of exposure expressed as cum U-Hg/year (intensity) among the 52 referyear $\geq 550 \mathrm{nmol} / \mathrm{l}$ ). (cum U-Hg/year = cumulative urinary mercury concentration per year)

\begin{tabular}{|c|c|c|c|c|c|c|c|c|c|c|c|c|c|c|c|c|c|c|}
\hline \multirow[t]{3}{*}{ Group } & \multirow{2}{*}{\multicolumn{2}{|c|}{ Age (years) }} & \multirow{2}{*}{\multicolumn{2}{|c|}{$\begin{array}{l}\text { Years since } \\
\text { exposure } \\
\text { cessation }\end{array}$}} & \multirow{2}{*}{\multicolumn{2}{|c|}{ Vocabulary }} & \multicolumn{8}{|c|}{ Benton visual retention test } & \multicolumn{4}{|c|}{ Word pairs retention, errors } \\
\hline & & & & & & & \multicolumn{4}{|c|}{ Correct $(\mathrm{N})$} & \multicolumn{4}{|c|}{ Errors $(N)$} & \multirow[b]{2}{*}{ Mean } & \multirow[b]{2}{*}{ Mean $_{a \mathrm{ajj}}{ }^{\mathrm{a}}$} & \multirow[b]{2}{*}{$\mathrm{SD}$} & \multirow[b]{2}{*}{ P-value } \\
\hline & Mean & $\mathrm{SD}$ & Mean & $\mathrm{SD}$ & Mean & $\mathrm{SD}$ & Mean & Mean $_{\mathrm{adj}}{ }^{\mathrm{a}}$ & $\mathrm{SD}$ & P-value & Mean & $\operatorname{Mean}_{a d j}{ }^{a}$ & $\mathrm{SD}$ & P-value & & & & \\
\hline $\begin{array}{l}\text { Referents } \\
\text { Low }\end{array}$ & 45.5 & 10.8 & . & . & 8.7 & 1.2 & 7.5 & 7.4 & 1.4 & 0.001 & 4.0 & 4.0 & 2.3 & 0.003 & 5.4 & 5.5 & 3.3 & 0.02 \\
\hline $\begin{array}{l}\text { exposed } \\
\text { High }\end{array}$ & 41.8 & 11.9 & 8.2 & 10.2 & 9.0 & 1.4 & 7.3 & 7.2 & 1.4 & 0.008 & 3.8 & 4.1 & 2.4 & 0.002 & 5.3 & 5.5 & 2.7 & 0.01 \\
\hline exposed & 50.5 & 8.5 & 21.5 & 9.3 & 8.4 & 1.4 & 6.3 & 6.6 & 1.6 & . & 5.8 & 5.1 & 2.8 & . & 7.2 & 6.4 & 3.2 & . \\
\hline P-value d & & & & & & & 0.003 & & & & 0.002 & & & & 0.03 & & & \\
\hline
\end{tabular}

${ }^{a}$ Adjusted for covariates. $\quad$ beast square difference $(\mathrm{P}<0.05)$, referring to comparisons between referents and workers with high exposure. adjustment for potential confounders (age, alcohol consumption, head injuries, shift work, vocabulary). 
The results of the other neuropsychological tests are shown in table 3 (see page 345). The performance on the Benton visual retention test (number of correct reproductions) and grooved pegboard test (both dominant and nondominant hand) was significantly poorer for all the exposed workers when compared with the referents. These differences remained statistically significant after control for potential confounding from age, vocabulary, alcohol consumption, head injuries, and shift work (not tabulated).

Only the test results of the Benton visual retention test and the grooved pegboard test differed between the 25 subjects with high cumulative exposure and the referents (table 4). The results among the workers with low cumulative exposure were not significantly different from the results in the reference group. A similar result was obtained (not tabulated) for 25 subjects with the longest duration of exposure. More differences were found when the sample was stratified according to the intensity of exposure (table 5). In addition to the Benton visual retention test and the grooved pegboard test, the high-exposure intensity group also had a poorer performance on the word pairs test (retention errors), the trailmaking test (parts A and B), and the digit symbol test. The biggest difference was found for the trailmaking test, part B. Results of the low-intensity exposure group were close to those of the referents.

As a further approach, the neuropsychological test results of all the participants were used as dependent variables in a stepwise multiple linear regression to assess the exposure measures (months exposed and intensity of exposure) while taking into account potential confounders (age, shift work, current alcohol consumption, head injuries, and vocabulary (table 6). The exposure intensity (cumulative urinary mercury index) appeared to be a better predictor for performance on the Benton visual retention test (number of correct responses), the trailmaking test (parts A and B), and the digit symbol test. For the Benton visual retention test (number of errors), the exposure intensity was nearly included in the model as an independent variable $(\mathrm{P}=0.052)$ (not tabulated). Exposure duration was the better predictor for the outcome of the grooved pegboard test.

As American norms related to age and duration of education were available for the trailmaking test (Norwegian norms were not available), the raw scores of the trailmaking test, part $\mathrm{B}$, were transformed to $\mathrm{T}$-scores (39). Figure 1 shows the results (in terms of T-scores) for the trailmaking test, part B, for the 52 referents, 50 exposed workers with a cumulative urinary mercury/year of $<550 \mathrm{nmol} /(1 \cdot$ year $)$, and the 25 workers exposed to the highest mean intensity $[\geq 550 \mathrm{nmol} /(1 \cdot$ year $)]$. The mean performance in the latter group was approximately $1 / 2$ a standard deviation lower than for the referents and the low-intensity exposure group and thus indicated the magnitude of the suggested effect of exposure on this test. When the material was stratified according to the duration of exposure, no significant difference was observed among the $1 / 3$ of the workers with the longest duration of exposure when they were compared with the other exposed workers or the referents (not shown).

\section{Discussion}

Several studies have reported neurobehavioral effects related to motor and cognitive functions $(3-20)$ in humans during ongoing exposure to mercury vapors. Contrary to the large number of studies on currently exposed workers, few epidemiologic studies have focused on the long-term effects on workers who are no longer exposed. The studies have mainly utilized neurological effect measures and have indicated a slight persistent impairment of the central nervous system after the cessation of exposure. The reported neurological effects have mainly been related to motor functions, such as decreased coordination and increased tremor $(22-25)$, or decreased sensation $(22,24,25)$.

Only 2 epidemiologic investigations using neuropsychological effect measures to study workers previously nts, the 50 workers with low exposure intensity [cum U-Hg/year $<550 \mathrm{nmol} /(\mathrm{l} \cdot$ year)], and 25 workers with high exposure intensity (cum U- $\mathrm{Hg} /$

\begin{tabular}{|c|c|c|c|c|c|c|c|c|c|c|c|c|c|c|c|c|c|c|c|}
\hline \multicolumn{8}{|c|}{ Grooved pegboard test } & \multicolumn{8}{|c|}{ Trailmaking test } & \multicolumn{4}{|c|}{ Digit symbol } \\
\hline \multicolumn{4}{|c|}{ Dominant (s) } & \multicolumn{4}{|c|}{ Nondominant (s) } & \multicolumn{4}{|c|}{ Part A (s) } & \multicolumn{4}{|c|}{ Part B (s) } & \multirow[b]{2}{*}{ Mean } & \multirow[b]{2}{*}{$\operatorname{Mean}_{a d j^{\mathrm{a}}}$} & \multirow[b]{2}{*}{$S D$} & \multirow[b]{2}{*}{ P-value } \\
\hline Mean & Mean $_{\mathrm{adj}}{ }^{\mathrm{a}}$ & $S D$ & $P$-value & Mean & Mean $_{\mathrm{adj}}{ }^{\mathrm{a}}$ & $S D$ & P-value & Mean & $\operatorname{Mean}_{\mathrm{adj}}^{\mathrm{a}}$ & $\mathrm{SD}$ & $P$-value & Mean & $\operatorname{Mean}_{\mathrm{adj}} \mathrm{a}^{\mathrm{a}}$ & $S D$ & P-value & & & & \\
\hline 70.9 & 71.1 & 11.6 & 0.01 & 76.3 & 77.1 & 11.8 & 0.001 & 33.7 & 33.6 & 12.5 & 0.01 & 100.3 & 100.0 & 53.5 & 0.001 & 8.5 & 8.6 & 1.8 & 0.02 \\
\hline 73.9 & 76.0 & 16.3 & . & 79.2 & 81.0 & 17.2 & 0.01 & 34.2 & 36.4 & 16.0 & 0.02 & 95.3 & 105.5 & 54.3 & $<0.001$ & 8.8 & 8.7 & 2.1 & 0.003 \\
\hline 79.7 & 74.7 & 14.9 & . & 88.4 & 83.0 & 17.0 & 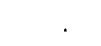 & 43.5 & 39.3 & 22.5 & . & 153.2 & 133.6 & 85.0 & ' & 7.4 & 7.6 & 1.7 & . \\
\hline 0.01 & & & & 0.001 & & & & 0.02 & & & & 0.001 & & & & 0.008 & & & \\
\hline
\end{tabular}

east square difference $(P<0.05)$, referring to comparisons between workers with low and high exposure.

Level of significance between the groups after 
Table 6. Results (intercepts and regression coefficients) from the stepwise multiple regression analysis for 75 former chloralkali workers exposed to mercury vapor and 52 referents. ${ }^{a}$ (cum U-Hg = cumulative urinary mercury concentration)

\begin{tabular}{|c|c|}
\hline Test & Result \\
\hline $\begin{array}{l}\text { Benton visual retention } \\
\text { test, correct (N) }\end{array}$ & $7.5^{b}-0.0009^{\circ}$ cum U-Hg/year \\
\hline \multicolumn{2}{|l|}{ Static steadiness (log) } \\
\hline Time, nondominant hand & $0.7^{\mathrm{b}}+0.001^{\mathrm{d}}$ months of exposure \\
\hline $\begin{array}{l}\text { Grooved pegboard test } \\
\text { Time (s), dominant hand }\end{array}$ & $\begin{array}{l}40.5^{\mathrm{b}}+0.7^{\mathrm{b}} \text { age }+0.04^{\mathrm{e}} \text { months of } \\
\text { exposure }\end{array}$ \\
\hline Time (s), nondominant hand & $\begin{array}{l}71.3^{\mathrm{b}}+0.6^{\mathrm{b}} \text { age }+9.5^{\mathrm{c}} \text { head injury } \\
-2.6^{\mathrm{e}} \text { vocabulary }+0.03^{\mathrm{l}} \text { months of } \\
\text { exposure }\end{array}$ \\
\hline \multicolumn{2}{|l|}{ Trailmaking test } \\
\hline Part A (s) & $8.6^{0}+0.6^{\mathrm{b}}$ age $+0.007^{\mathrm{d}} \mathrm{cum} \mathrm{U}-\mathrm{Hg} /$ year \\
\hline Part B (s) & $\begin{array}{l}113.4^{\mathrm{e}}+2.4^{\mathrm{b}} \text { age }-14.2^{\mathrm{b}} \text { vocabulary } \\
+0.04^{\mathrm{c}} \mathrm{cum} \mathrm{U}-\mathrm{Hg} / \text { /year }\end{array}$ \\
\hline Digit symbol & $\begin{array}{l}5.4^{\mathrm{b}}+0.4^{\mathrm{h}} \text { vocabulary } \\
-0.0008^{\mathrm{c}} \text { cum U-Hg/year }\end{array}$ \\
\hline \multicolumn{2}{|c|}{$\begin{array}{l}\text { a Independent variables: months exposed, intensity of exposure (cum } \\
\text { U-Hg/year); age, current alcohol consumption; head injury, shift work; } \\
\text { vocabulary (WAIS-R). }\end{array}$} \\
\hline \multicolumn{2}{|c|}{ 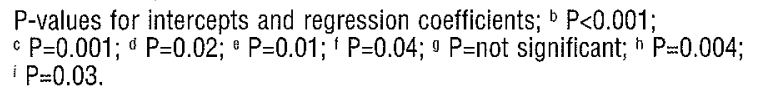 } \\
\hline
\end{tabular}

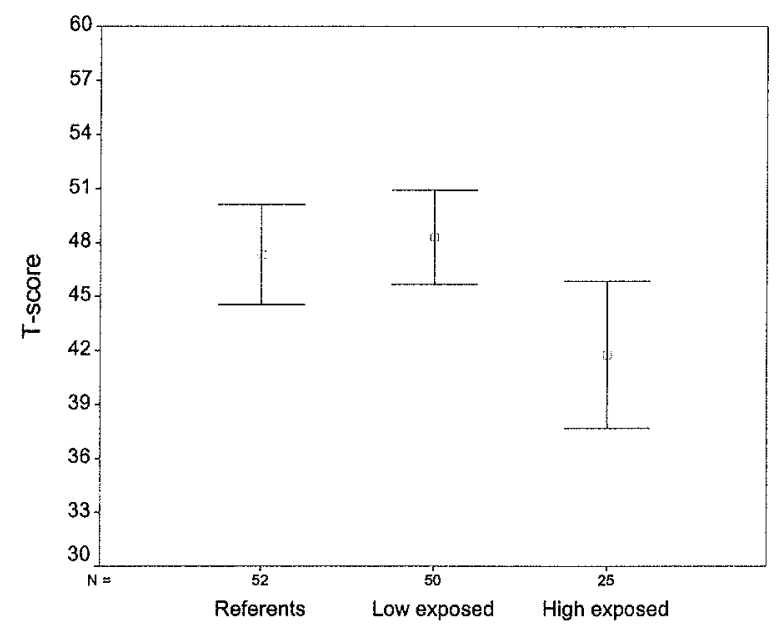

Figure 1. Results (mean and $95 \%$ confidence interval) of the trailmaking test, part B (expressed as T-scores), of 52 referents, 50 exposed workers with a low mean level of urinary mercury each year of exposure [cumulative urinary mercury/year $<550 \mathrm{nmol} /(1 \cdot$ year $)$ ], and 25 exposed workers with high mean urinary mercury during their time of exposure [cumulative urinary mercury/year $\geq 550 \mathrm{nmol} /(1 \cdot$ year $)$ ].

exposed to mercury vapors are available to our knowledge $(26,27)$. Fine et al (27) found poorer performance on a hand-eye coordination test for 247 workers formerly exposed to mercury vapors when they were compared with unexposed referents. Overall the exposed workers performed slightly poorer on tests for psychomotor skills. Fine et al (27) also used a limited selection of cognitive tests without detecting poorer cognitive functions in these workers. Exposure to mercury vapors had ceased approximately 20 years prior to the study. In a study of former mercury miners, deteriorated motor coordination, simple reaction time, and short-term memory were found. Furthermore, a reduced performance on tests for hand-eye coordination, motor speed, and reading speed was reported in relation to duration of exposure. The history of prior mercury intoxication showed no significant correlation with current neurobehavioral performance overall, but the age-related deterioration in performance in several tests was reported to be more pronounced among the older ex-miners with a prior history of intoxication. Exposure had ceased approximately 20 years prior to the study (26).

The results on the WAIS-R subtests in the present study did not indicate an effect of past exposure to mercury vapors on general intellectual function. Both on the vocabulary test, considered as a fairly robust measure of premorbid intellectual function, and the similarities test, described as a WAIS-R subtest little affected by socioeconomic and educational background (29), the results were almost identical when the formerly exposed subjects were compared with the referents. These results further suggest that the exposed subjects and the referents were comparable with regard to intellectual functioning and, consequently, were of similar intellectual background. This assumption is supported by the identical mean duration of formal education of the studied groups. As the formerly exposed subjects and the referents were also comparable with respect to age and their background as industrial workers, one may conclude that the selected referents were comparable with the formerly exposed workers with regard to several critical background variables in neuropsychological studies. As the chloralkali plant under scrutiny was closed more than 1 year before the examinations and the referents were currently employed workers, a possible selection of healthier referents is possible, but not likely however, as only 7 of the examined exposed subjects were unemployed at the time of the examination ( 4 due to early retirement and 3 due to diseases not leading to exclusion).

Few significant differences emerged between the exposed group as a whole and the referents in our study. However, the subgroups with a particularly high exposure appeared to have reduced performance on the Benton visual retention test, the trailmaking test (parts $\mathrm{A}$ and B), the digit symbol test, the grooved pegboard test, and the word pairs test (retention errors).

The Benton visual retention test involves visuoconstructive capacities and visual memory. This test did not discriminate between previously mercury-exposed lithium production workers and referents (27), and the test was not administered to previously exposed Japanese mercury miners (26). Soleo et al (12) did not observe poorer performance on this test in a small study on currently exposed workers who were compared with referents. The workers with the highest intensity of exposure 
also had a statistically significant reduced performance on the word pairs test (retention errors), which is another test of memory and learning. However, several statistical comparisons were made in our study, and the word pairs test results were not associated with exposure measures in the multiple linear regression analysis. It could therefore be a random finding. Still, several studies on currently exposed populations have reported reduced performance on memory tests $(9,10,14,18)$, and the possibility cannot be excluded that the observed poorer performance on the word pairs test among the workers with the highest exposure intensity was real.

The grooved pegboard test is a test of manual dexterity and complex motor coordination. The poorer performance on this test among the exposed workers is in accordance with the observation of impaired coordination in the clinical neurological examination of the same workers $(24,25)$. Impaired manual dexterity or coordination has been suggested as an effect of past exposure to mercury vapors in other neuropsychological studies of previously exposed workers $(26,27)$. Workers exposed to mercury vapors at the time of examination have been shown to have poorer results in similar tests (10), whereas other studies on populations with lower exposure have shown no difference between exposed subjects and referents $(11,17,18)$. Neither did Bluhm et al (20) detect impaired test results for the grooved pegboard test among workers who had experienced acute intensive exposure.

The results of the trailmaking test (parts $\mathrm{A}$ and $\mathrm{B}$ ) were consistently reduced in the highest exposure group. These tests mainly measure attention, motor speed, visual scanning and visuomotor tracking. They were not applied in the 2 neuropsychological studies of previously exposed workers $(26,27)$, but poorer performance has been reported for currently exposed populations $(16,18)$. It is an interesting observation that workers with high acute intensive exposure showed a substantial improvement in the test results of parts A and B after chelation with 2,3-dimercaptosuccinic acid (20). The digit symbol test is a test measuring functions similar to those measured by the trailmaking test. Reduced performance in the highest exposed group could therefore be in accordance with the poorer performance observed for the trailmaking test among the same workers. This test was not administered to the Japanese ex-miners (26), and a similar test (symbol digit) did not discriminate between the previously exposed American lithium plant workers and their referents (27).

In summary, tests suggesting impairment in motor, psychomotor, visuomotor functions, and attention discriminated between the exposed groups and the referents in our study.

We used three indicators of past exposure in this study, exposure duration, the intensity of exposure, and a combination thereof (cumulative exposure). When we stratified the exposed subjects according to these exposure indicators, the exposure intensity appeared to discriminate better between the groups than the exposure duration or the cumulative exposure did. The regression analysis suggested duration of exposure as the more appropriate exposure variable for the outcome on the grooved pegboard test. However, for the trailmaking test (parts A and B) the Benton visual retention test, and the digit symbol test, the intensity of exposure appeared to be the most appropriate predictor. These differences could perhaps suggest that different neurological functions may be harmed by different mechanisms, one involving a higher intensity of exposure, and one involving continuing, but perhaps lower, exposure. It should also be noted that the subjects with a low intensity of exposure or a low cumulative exposure, as defined in our study, had an intact performance on the tests used in the study, indicating that a higher level of exposure might be required to induce long-term neuropsychological sequelae. The workers who had experienced the highest intensity of exposure had an average exposure-free interval of 21.5 years, showing that the poorer performance may be a real long-term effect, which is also the experience gained with the former Japanese mercury miners (26) and the formerly exposed American lithium production workers (27). The workers who had experienced a lower intensity of exposure had an average exposurefree interval of 8.2 years prior to the examinations. This finding could suggest that, if they have had a poorer neuropsychological performance during exposure, it may have been reversible in the time span from the cessation of exposure to the current examinations. Whether the neuropsychological tests discriminating between the exposed workers and the referents are more sensitive to long-term effects of mercury exposure or are more persistent after exposure cessation cannot be decided by this study design.

In conclusion, the results of our study suggest that previous exposure to mercury vapors does not affect the general intellectual level or the ability for logical reasoning among the workers. The results suggest a slight persistent effect of inorganic mercury on the central nervous system, mainly on motor functions and attention, but also possibly in relation to visual pathways.

\section{References}

1. World Health Organization (WHO). Inorganic mercury. Geneva: WHO, 1991. Environmental health criteria 118.

2. Hänninen $\mathrm{H}$. Behavioral effects of occupational exposure to mercury and lead. Acta Neurol Scand Suppl 1982;92:16775 .

3. Wood RW, Weiss AB, Weiss B. Hand tremor induced by industrial exposure to inorganic mercury. Arch Environ Health

Scand J Work Environ Health 1999, vol 25, no 4 
$1973 ; 26: 249-52$.

4. Fawer RF, de Ribaupierre Y, Guillemin MP, Berode M, Lob $M$. Measurement of hand tremor induced by industrial exposure to metallic mercury. Br J Ind Med 1983;40:204-8.

5. Miller JM, Chaffin DB, Smith RG. Subclinical psychomotor and neuromuscular changes in workers exposed to inorganic mercury. Am Ind Hyg Assoc J 1975;36:725—33.

6. Langolf GD, Chaffin DB, Henderson R, Whittle HP. Evaluation of workers exposed to elemental mercury using quantitative tests of tremor and neuromuscular functions. Am Ind Hyg Assoc J 1978;39:976-84.

7. Roels H, Abdeladim S, Braun M, Malchaire J, Lauwerys R. Detection of hand tremor in workers exposed to mercury vapor: a comparative study of three methods. Environ Res 1989;49:152-65.

8. Camerino D, Cassitto MG, Desideri E, Angotzi G. Behavior of some psychological parameters in a population of a $\mathrm{Hg}$ extraction plant. Clin Toxicol 1981;18:1299-309.

9. Triebig G, Schaller K-H. Neurotoxic effects in mercury-exposed workers. Neurobehav Toxicol Teratol 1982;4:717-20.

10. Piikivi L, Hänninen H, Martelin T, Mantere P. Psychological performance and long-term exposure to mercury vapors. Scand J Work Environ Health 1984;10:35-41.

11. Uzzel BP, Oler J. Chronic low-level mercury exposure and neuropsychological functioning. J Clin Exp Neuropsychol 1986;8:581—93.

12. Soleo L, Urbano ML, Petrera V, Ambrosi L. Effects of low exposure to inorganic mercury on psychological performance. Br J Ind Med 1990;47:105-9.

13. Smith PJ, Langolf GD. The use of Sternberg's memory-scanning paradigm in assessing effects of chemical exposure. Hum Factors 1981;23:701-8.

14. Smith PJ, Langolf GD, Goldberg J. Effects of occupational exposure to elemental mercury on short term memory. $\mathrm{Br} \mathrm{J}$ Ind Med 1983;40:413-9.

15. Smith PJ. Short-term memory scanning is related to memory span and mercury exposure [dissertation]. Ann Arbor (MI): The University of Michigan, 1979.

16. Echeverria D, Aposhian HV, Woods JS, Heyer NJ, Aposhian $\mathrm{MM}$, Bittner Jr AC, et al. Neurobehavioral effects from exposure to dental amalgam $\mathrm{Hg}^{0}$ : new distinctions between recent exposure and $\mathrm{Hg}$ body burden. FASEB 1998;12:971-80.

17. Shapiro IM, Cornblath DR, Sumner AJ, Uzzell B, Spitz LK, Ship II, et al. Neurophysiological and neuropsychological function in mercury-exposed dentists. Lancet 1982;1:114755.

18. Ngim CH, Foo SC, Boey KW, Jeyaratnam J. Chronic neurobehavioural effects of elemental mercury in dentists. $\mathrm{Br} \mathrm{J}$ Ind Med 1992;49:782-90.

19. Ritchie KA, Macdonald EB, Hammersley R, O'Neill JM, McGowan DA, Dale IM, et al. A pilot study of the effect of low level exposure to mercury on the health of dental surgeons. Occup Environ Med 1995;52:813-7.

20. Bluhm RE, Bobbitt RG, Welch LW, Wood AJJ, Bonfiglio JF, Sarzen C, et al. Elemental mercury vapour toxicity, treatment, and prognosis after acute, intensive exposure in chloralkali plant workers, part I: history, neuropsychological findings and chelator effects. Hum Exp Toxicol 1992;11:201-10.

21. Magos L. Physiology and toxicology of mercury. In: Sigel A, Sigel H, editors. Metal ions in biological systems; mercury and its effects on environment and biology, vol. 34. New York (NY): Marcel Dekker Inc, 1997:321—70.
22. Albers JW, Kallenbach LR, Fine LJ, Langolf GD, Wolfe RA, Donofrio PD, et al. Neurological abnormalities associated with remote occupational elemental mercury exposure. Ann Neurol 1988;24:651—9.

23. He FS, Zhow XR, Lin BX, Xiung YP, Chen SY, Zhang SL, et al. Prognosis of mercury poisoning in mercury refinery workers. Ann Acad Med Singapore 1984;13:389—93.

24. Andersen A, Ellingsen DG, Mørland T, Kjuus H. A neurological and neurophysiological study of chloralkali workers previously exposed to mercury vapour. Acta Neurol Scand 1993;88:427-33.

25. Ellingsen DG, Mørland T, Andersen A, Kjuus H. Relation between exposure related indices and neurological and neurophysiological effects in workers previously exposed to mercury vapour. Br J Ind Med 1993;50:736-44.

26. Kishi R, Doi R, Fukuchi Y, Satoh H, Satoh T, Ono A, et al Residual neurobehavioural effects associated with chronic exposure to mercury vapour. Occup Environ Med 1994;51:3541.

27. Fine $\mathrm{L}$ and the University of Michigan research team. Health evaluation of Y-12 workers formerly exposed to mercury. Ann Arbor (MI): The University of Michigan Schools of Engineering, Medicine and Public Health, 1987.

28. Ellingsen DG, Holland RI, Thomassen Y, Landro-Olstad M, Frech W, Kjuus $H$. Mercury and selenium in workers previously exposed to mercury vapour at a chloralkali plant. Br J Ind Med 1993;50:745-52.

29. Lezak M. Neuropsychological assessment. 3rd ed. Oxford: Oxford University Press, 1995.

30. White RF, Proctor SP. Research and clinical criteria for development of neurobehavioral test batteries. J Occup Med 1992;34:140-8.

31. Wechsler D. WAIS-R manual. New York (NY): Psychological Corporation, 1981.

32. Andersen R. Verbal and visuo-spatial memory. Scand J Psychol 1976;17:198-204.

33. Hamsher KdeS, Benton AL, Digre K. Serial digit learning: normative and clinical aspects. $J$ Clin Neuropsychol 1980;2:39-50.

34. Ryan CM, Morrow LA, Bromet EJ, Parkinson DK. Assessment of neuropsychological dysfunction in the workplace: normative data from the Pittsburgh occupational exposures test battery. J Clin Exp Neuropsychol 1987;9:665—79.

35. Benton AL. Revised visual retention test: clinical and experimental applications. 4th ed. New York (NY): The Psycholog ical Corporation, 1974

36. Kimura D. Right temporal lobe damage. Arch Neurol 1963;8:264-71.

37. Baker EL, Letz RE, Fidler AT, Shalat S, Plantamura D, Lyndon M. A computer-based neurobehavioral evaluation system for occupational and environmental epidemiology: methodology and validation studies. Neurobehav Toxicol Teratol $1985 ; 7: 369-77$.

38. Kløve H. Validation studies in adult clinical neuropsychology. In: Reitan RM, Davidson LA, editors. Clinical neuropsychology: current status and applications. New York (NY): John Wiley, 1974.

39. Heaton RK, Grant I, Matthews CG. Comprehensive norms for an expanded Halstead Reitan Battery. Odessa (FL): Psychological Assessment Resources Inc, 1991.

Received for publication: 8 May 1998 